\title{
Self-reported health and associated factors among the immigrant populations in Norway
}

\author{
Ahmed A. Madar ${ }^{1}$ - Bjørn Heine Strand ${ }^{1,2} \cdot$ Haakon E. Meyer ${ }^{1,2}$
}

Received: 23 September 2019 / Accepted: 26 March 2020 / Published online: 18 April 2020

(C) The Author(s) 2020

\begin{abstract}
Aim The immigrant population continues to increase in Norway, and Somali immigrants and their descendants are presently the largest non-Western group. We have limited knowledge about the health status in this population. The aim of this study was to assess self-perceived health status among Somalis in Norway.

Method We used data from a study assessing risk factors for lifestyle diseases among Somali immigrants in Oslo, which was conducted between December 2015 and October 2016, among men and women aged 20-73 who were living in the Sagene borough in Oslo.

Results The study population included 221 participants (112 females and 110 males). Overall, $78 \%$ of the participants (70\% of females and $86 \%$ males) rated their health status as good or very good. Women had poorer self-reported health $(p=0.003)$ than men. Being unemployed and having diabetes, stress, and sleeping problems were associated with poor self-reported health, but time lived in Norway, education level, Norwegian language proficiency, and high BMI were not significantly associated. Around $2 / 3$ of the participants reported being physically inactive, while around half reported walking or moving more than 30 min per day. Self-reported chronic diseases such as diabetes and hypertension were 5\% and $9 \%$ respectively.

Conclusion This study has shown the different patterns of self-reported health status among Somali immigrants in Norway, as associated with gender, age, psychosocial conditions, and employment status. Further research is needed to explain why Somali women in Norway have poorer self-reported health than men. The findings from this study should provide direction to healthcare providers for improving health among immigrants, for example through implementing a community-driven and culturally appropriate lifestyle intervention program.
\end{abstract}

Keywords Self-reported health $\cdot$ Psychosocial health immigrants $\cdot$ Somalis $\cdot$ Norway

\section{Introduction}

Self-perceived health is a commonly-used health indicator worldwide. It reflects a person's subjective health, which has shown to be a strong predictor of physical functioning, morbidity, and mortality (Kaplan et al. 1996; Idler and Benyamini

Ahmed A. Madar

a.a.madar@medisin.uio.no

Bjørn Heine Strand

heine@fhi.no

Haakon E. Meyer

h.e.meyer@medisin.uio.no

1 Department of Community Medicine and Global Health, Institute of Health and Society, University of Oslo, Oslo, Norway

2 Norwegian Institute of Public Health (NIPH), Oslo, Norway
1997; Roos et al. 2005; DeSalvo et al. 2006; Mavaddat et al. 2014). An individual's self-perceived health can be related to various influencers, including but not limited to medical health status, physical and mental wellbeing, living conditions, and healthful behaviors.

This may include social conditions related to upbringing, education, environment, work, diet, and physical activity (Nielsen and Krasnik 2010). Such behaviors and conditions greatly affect an individual's measurable and perceived health, and equalization of social disparities in different communities is an important contributor to bettering the public health of societies. In Western countries, the awareness of disparity in health between the majority populations and immigrant groups has increased (Nielsen and Krasnik 2010; La ParraCasado et al. 2017). Factors such as health risks in immigrants' home countries, problems during and after migration, and poor socioeconomic conditions related to challenges with resettlement and integration may be leading to increased stress 
and less healthful behaviors, and thus poor overall health among immigrants (Jervelund et al. 2017).

In Norway, there are substantial social inequalities in health and, in general, self-perceived health among immigrants is worse than among the ethnic Norwegian population (Norwegian Institute of Public Health 2018). Results from a survey on living conditions among immigrants revealed that while $86 \%$ of ethnic Norwegians perceived their health as good or very good, only about $73 \%$ of non-Western immigrants reported the same (Vrålstad and Wiggen 2017). Immigrant women rate their health less positively than men, and the perception of health as good or very good decreases with age in the immigrant population more considerably than in the non-immigrant Norwegian population. In a study where the five largest immigrant groups in Norway were included, non-immigrant Norwegians reported good health more frequently than the immigrant groups (Kumar et al. 2008). However, there are differences between immigrants from different countries. Women from Pakistan and Turkey reported good health less frequently than both other immigrant women and non-immigrant Norwegians (Kumar et al. 2008).

According to Statistics Norway, Somalis and their offspring constitute the largest non-Western immigrant group in Norway, with a population of approximately 41,000 persons. Most Somali immigrants in Norway migrated due to the domestic civil war in Somalia that began in the 1980s, but the majority arrived after the mid-1990s, either as asylum seekers or through family reunions (SSB 2019). Being a relatively new immigrant group, knowledge about their health status is limited, and Somalis were not included in the Oslo Immigrant Health Study in 2001-2002. Somalis in Norway stand out as experiencing the most disadvantaged position by any socioeconomic standards, such as poor living conditions and unemployment, and they face a number of challenges, such as language barriers (Vrålstad and Wiggen 2017; Markussen 2018). We have recently reported that persons with Somali immigrant background in Oslo have low physical activity and high prevalence of overweight, obesity, and high waist circumference (Ahmed et al. 2018; Ahmed et al. 2019). These conditions can to lead to decreased health status. Thus, we hypothesized that the Somali immigrant population in Norway would have poorer health than the general Norwegian population. The main purpose of this study was to study the self-reported health and associated factors among Somali immigrants in Norway.

\section{Design, methods, and material}

This paper's data originates from a cross-sectional study assessing risk factors for lifestyle diseases among Somali immigrants in Oslo, Norway, conducted between December 2015 and October 2016 (Ahmed et al. 2019).
The eligible participants were male and female adults of Somali origin, aged 20-73 years, who lived in the Sagene borough in Oslo. This district was selected because it has one of the highest populations and concentrations of persons of Somali origin in the city. Collaboration was established with local Somali organizations, a healthy life center, and the district medical officer, with all contributing to the planning of the study. Information about the study was shared through the local Somali radio and community centers in the district. An attempt to contact every adult person of Somali background living in the district was made, and those available were invited to participate in the study. Pregnant women were excluded from participation. A total of 272 persons were identified as potentially eligible, of whom 50 persons either declined participation or were not eligible.

\section{Data collection}

Information about gender, age, education, smoking habits, and length of stay in Norway was collected using a questionnaire. The questionnaire included questions about self-reported health (on a 5-point scale) and history of chronic diseases [diabetes, hypertension, hyperlipidemia and chronic obstructive pulmonary disease (COPD), heart attack, stroke or angina pectoris], smoking habits, physical activity, medication use, and psychosocial conditions (stress and sleeping disorders). The questionnaire was previously used in the Oslo Immigrant Health Study, but this was not validated for our study group. However, it was revised and pilot tested in a smaller group of Somalis.

\section{Indicators and variables}

\section{Self-reported health status}

Self-reported health status was measured through a single question: "Would you say your overall health is very good, good, fair, poor or very poor?" A dichotomous outcome variable was created $(0=$ fair, poor or very poor; $1=$ good, or very good) for comparison with other studies.

\section{Statistical methods}

Analysis of the data was performed using the statistical software package IBM SPSS Statistics version 22. Descriptive statistics are presented as means and standard deviations (SD). To test for differences in self-reported health according to explanatory variables, we used an independent-sample $t$ test for continuous variables and a chi-squared test for categorical variables. The relationships between self-reported health status and explanatory variables were tested using logistic regression models. The significance level was set to $p<0.05$. 


\section{Ethics}

The study was approved by the Regional Committee for Medical and Health Research Ethics (study code: 2015/1552 REK South-East). Informed written consent was obtained from all participants.

\section{Results}

A total of 221 participants (112 females and 110 males), aged 20-73 years, were included in the study. Generally, men had higher levels of education and higher rates of employment than women (Table 1), and more men reported good Norwegian language proficiency, although there was no gender difference with respect to time lived in Norway.

\section{Self-reported health}

Men reported good health more frequently than women $(p<0.01): 30 \%$ versus $15 \%$. There was no gender difference with respect to stress patterns and sleeping problems, but men reported more hard physical activities (Table 2).

\section{Self-reported chronic diseases}

The prevalence of self-reported diabetes was $5 \%$, and there was no gender difference $(p=0.8)$ (Table 2). Around 91\% (10/
11) of those who reported diabetes were taking diabetes medicine. Also, 9\% reported having high blood pressure, with no gender difference $(p=0.2)$, all of whom reported taking antihypertensive drugs. Apart from one male participant, all the persons who reported having hypertension were older than 45 years, and half of them also had diabetes. Chronic obstructive pulmonary disease was not reported, but one female and one male over the age of 45 years reported having hypercholesterolemia. Self-reported prevalence of myocardial infarction $(n=1)$, stroke $(n=2)$, and angina $(n=2)$ was low. All three with myocardial infarction and stroke were men.

\section{Psychosocial conditions}

Around $38 \%$ of the women and $44 \%$ of the men reported one or multiple periods of stress. However, the proportion who experienced permanent stress was low (4\%), and there was no gender difference $(p=0.4)$ (Table 2). Three-quarters reported that they never or a few times a year had sleeping problems, whereas $13 \%$ reported having sleeping problems more than once a week. There was no gender difference with respect to sleep $(p=0.4)$.

\section{Physical activity}

Over $70 \%$ of the participants reported being physically inactive, while around half reported walking more than $30 \mathrm{~min}$ per
Table 1 Characteristics of the study population

\begin{tabular}{llll}
\hline & All & Female & Male \\
\hline Gender: \% $(n)$ & $100(221)$ & $51(112)$ & $49(110)$ \\
Mean age, years (SD) & $39(11)$ & $38(10)$ & $40(12)$ \\
Education: \% $(n)$ & & & \\
Primary or less than primary school & $50(110)$ & $65(73)$ & $34(37)$ \\
Secondary school & $30(67)$ & $23(26)$ & $29(32)$ \\
High school or university & $20(45)$ & $12(13)$ & $66(72)$ \\
Civil status: \% (n) & & & $27(30)$ \\
Married & $65(144)$ & $64(72)$ & $7(8)$ \\
Non-married & $26(58)$ & $25(28)$ & $13.9(1-30)$ \\
Divorced/separated & $9(20)$ & $11(12)$ & $16(17)$ \\
Years lived in Norway: mean (min-max) & $13(1-30)$ & $12.2(1-25)$ & $54(60)$ \\
Norwegian language proficiency: \% $(n)$ & & & $30(33)$ \\
Poor & $20(45)$ & $25(28)$ & $62(68)$ \\
Middle & $56(125)$ & $58(65)$ & $19(21)$ \\
Good & $24(52)$ & $17(19)$ & $19(21)$ \\
Employment status: \% unemployed $(n)$ & & & \\
Yes & $43(95)$ & $24(27)$ & $22(27)$ \\
No & $20(46)$ & $54(60)$ & \\
Other & $37(81)$ & & \\
\hline
\end{tabular}

* studying, participate courses or introduction programme 
Table 2 Self-reported health, psychosocial conditions, and physical activities

\begin{tabular}{|c|c|c|c|}
\hline & All & Female & Male \\
\hline \multicolumn{4}{|l|}{ Self-reported health: $\%(n)^{*}$} \\
\hline Poor & $22(49)$ & $30(34)$ & $14(15)$ \\
\hline Good & $78(171)$ & $70(78)$ & $86(94)$ \\
\hline \multicolumn{4}{|l|}{ Known diabetes: $\%(n)$} \\
\hline Yes & $5(11)$ & $5.4(6)$ & $4.5(5)$ \\
\hline \multicolumn{4}{|l|}{ Known hypertension: \% (n) } \\
\hline Yes & $9(19)$ & $6(7)$ & $11(12)$ \\
\hline \multicolumn{4}{|l|}{ Psychosocial conditions } \\
\hline \multicolumn{4}{|l|}{ Stress at home or work: $\%(n)$} \\
\hline Never & $55(122)$ & $58(65)$ & $52(57)$ \\
\hline Experienced periods of stress & $31(69)$ & $30(34)$ & $32(35)$ \\
\hline Experienced multiple periods of stress & $10(22)$ & $8(9)$ & $12(18)$ \\
\hline Experienced permanently with stress & $4(8)$ & $4(4)$ & $4(4)$ \\
\hline \multicolumn{4}{|l|}{ Sleeping problems: $\%(n)$} \\
\hline Never, or a few times a year & $75(165)$ & $76(86)$ & $72(79)$ \\
\hline 1-2 times a month & $9(20)$ & $9(10)$ & $9(10)$ \\
\hline About once a week & $3(7)$ & $3(3)$ & $4(4)$ \\
\hline More than once a week & $13(29)$ & $12(13)$ & $15(16)$ \\
\hline \multicolumn{4}{|l|}{ Physical activity } \\
\hline \multicolumn{4}{|c|}{ Light exercise (not sweat or feel out of breath), h/week: \% (n) } \\
\hline$<1$ & $70(156)$ & $67(75)$ & $74(81)$ \\
\hline $1-2$ & $16(35)$ & $21(23)$ & $11(12)$ \\
\hline$>3$ & $14(30)$ & $12(14)$ & $15(16)$ \\
\hline \multicolumn{4}{|c|}{ Hard physical activity (sweat and feel out of breath), h/week: \% (n) } \\
\hline$<1$ & $76(168)$ & $91(102)$ & $61(66)$ \\
\hline $1-2$ & $7(15)$ & $5(6)$ & $8(9)$ \\
\hline$>3$ & $17(38)$ & $4(4)$ & $31(34)$ \\
\hline \multicolumn{4}{|c|}{ Walk, or move about in some other way, $\min /$ day: $\%(n)$} \\
\hline$<10$ & $11(25)$ & $16(18)$ & $6(7)$ \\
\hline $10-30$ & $41(91)$ & $43(48)$ & $40(43)$ \\
\hline$>30$ & $48(105)$ & $41(46)$ & $54(58)$ \\
\hline
\end{tabular}

$* 0=$ poor and very poor, $1=$ good and very good

day. However, more men reported being engaged in hard physical activities.

\section{Smoking and alcohol consumption}

As previously reported (Ahmed et al. 2019), smoking and alcohol habits varied enormously with gender. No females reported smoking or alcohol consumption, while 19\% of males reported smoking daily and nine males reported alcohol consumption.

\section{Anthropometric measurements}

As previously reported, a large proportion of men and women are overweight and obese (61\% and $78 \%$ respectively)
(Ahmed. et al. 2018), and the obesity rate is substantially higher among women than men $(p<0.001)$.

\section{Associated factors with poor self-reported health}

After adjustment for age and gender, unemployment, sleep problems, and stress were associated with poor self-reported health. Length of stay in Norway, education level, diabetes, and Norwegian language proficiency were not associated with self-reported health. For both women and men, poor selfreported health increased with increasing age (Table 3 ).

\section{Discussion}

Our study provides estimates of self-reported health status in Somali immigrants in the Sagene borough in Oslo, Norway. We found that the prevalence of self-reported good health in males and females was $86 \%$ and $70 \%$ respectively. The prevalence of known diabetes and hypertension was 5\% and 9\% respectively. Psychosocial aspects of health and employment status were associated with self-reported health.

There is limited data on health status among Somalis, both in Norway and in their home countries, but our results concur with previous research, which has shown that around $80 \%$ of Somalis rated their health as good or very good (SSB 2010). In addition, our findings confirm that women report poorer health status compared to men (Iglesias et al. 2003; Kumar et al. 2008). Generally, in Norway, a lower proportion of immigrants consider their health as good or very good compared to the native Norwegian population (73\% vs $83 \%$ ) (Kumar et al. 2008). However, the proportion of Somali men who rated their health status as good is similar to that of ethnic Norwegians, and was higher compared to other immigrant groups (Kumar et al. 2008). Despite Somali women having reported poorer health status compared to men, $70 \%$ of Somali women in our study rated their health status higher than other immigrant groups did, with proportions of good or very good self-reported health varying among other groups between $31 \%$ and $61 \%$ (Kumar et al. 2008).

Socio-economic factors could be playing a role in the gender difference. Socio-economic factors such as income, education, time lived in the host country, language proficiency, and health-related conditions were previously found to be associated with self-reported health among immigrants to Norway (Roos et al. 2005; Kumar et al. 2008). However, in our study, being unemployed and experiencing psychosocial problems (stress and sleeping problems) were the only factors associated with poor self-reported health, which corresponds with what was found among Somali immigrants in Finland (Rask et al. 2016).

Further, a systematic review on the self-perceived health of migrants in Europe found that most immigrant groups are 
Table 3 Odds ratio, with $95 \%$ confidence interaval $(\mathrm{CI})$, for poor versus good self-reported health, and potentially associated factors in participants of Somali origin residing in Norway (n 221) aged $20-73$ years

\begin{tabular}{|c|c|c|c|c|}
\hline \multirow[t]{2}{*}{ Explanatory variables } & \multicolumn{2}{|l|}{$\mathrm{OR}^{*}$} & \multicolumn{2}{|l|}{ Adjusted OR } \\
\hline & OR $(95 \% \mathrm{CI})$ & $P$ value & OR $(95 \% \mathrm{CI})^{\dagger}$ & $P$ value \\
\hline Female gender & $2.73(1.39,5.38)$ & $<0.01$ & $5.0(2.1,11.80)$ & $<0.01$ \\
\hline Age (per year) & $1.10(1.05,1.12)$ & $<0.01$ & $1.09(1.05,1.14)$ & $<0.01$ \\
\hline Diabetes (yes versus no) & $10.9(2.79,43.3)$ & $<0.01$ & $4.2(0.96,18.63)$ & 0.056 \\
\hline Sleeping problems ${ }^{\S}$ & $2.72(1.27,5.86)$ & $<0.01$ & $3.7(1.46,9.82)$ & $<0.01$ \\
\hline Stress $^{\#}$ & $1.70(0.89,3.23)$ & 0.10 & $2.70(1.16,6.29)$ & 0.02 \\
\hline Education (low versus high) & $1.24(0.65,2.36)$ & 0.5 & $0.40(0.16,1.28)$ & 0.14 \\
\hline Norwegian proficiency ${ }^{\mathbb{I I}}$ & $2.08(1.01,4.3)$ & 0.05 & $1.0(0.40 ; 2.50)$ & 0.9 \\
\hline Length of stay in Norway (years) & $1.04(0.99,1.09)$ & 0.12 & $1.0(0.93,1.07)$ & 0.9 \\
\hline Employment (unemployed versus employed) & $3.40(1.68,6.89)$ & $<0.01$ & $3.88(1.45,7.88)$ & $<0.01$ \\
\hline \multicolumn{5}{|l|}{ * adjusted for age and gender } \\
\hline \multicolumn{5}{|c|}{$\dagger$ adjusted for variables that are significant in simple regression } \\
\hline \multicolumn{5}{|c|}{$\S$ sleeping disorder (coded as $0=$ never, $1=$ once/week or more) } \\
\hline \multicolumn{5}{|c|}{ \# stress (coded as $0=$ never or single periods, $1=$ several periods or permanent) } \\
\hline \multicolumn{5}{|c|}{ II Norwegian proficiency (coded $0=$ no good, $1=$ good) } \\
\hline
\end{tabular}

disadvantaged compared to the host population, even after controlling for gender, age, and socio-economic factors (Nielsen and Krasnik 2010). Among immigrants in Norway, physical and mental health is better among those who have high education, who are employed, and/or who are in a good economic situation (Kumar et al. 2008; Abebe et al. 2014). In our study, unemployment and chronic disease were associated with self-rated poor health. However, factors such as language proficiency, education, and length of stay in Norway were not associated with self-reported health. The association between the educational gradient and health is very strong for the host population. However, among immigrants, there is no such connection. This has been explained with respect to how difficult it is for immigrants to have their education from the years prior to coming to Norway recognized in Norway (Vrålstad and Wiggen 2017).

Short sleep duration and insomnia were the most commonly reported sleep problems, and were among the most common health issues in all age groups. Insomnia increases the risk of developing other health problems and also has indirect costs, such as increased risk of accidents and decreased work capacity (Javaheri and Redline 2017; Bertisch et al. 2018). Our results are consistent with previous findings that persons who experienced sleeping problems more than once per week reported poor health.

Compared to the other five largest non-Western immigrant groups in Norway, Somali women and men in our study had a lower prevalence of chronic diseases and conditions such as diabetes, hypertension, and hypercholesterolemia, apart from those of Iranian background (Kumar.et al. 2008). Similar results have been observed in a study conducted in the Netherlands, in which Somalis, as a group, reported the least amount of chronic conditions, post-traumatic stress disorder
(PTSD), and depression and anxiety (Gerritsen et al. 2006). These differences may be related to healthful behaviors. In our study, almost all women neither drank any alcohol nor smoked, while few men drank, and the prevalence of current smoking (19\%) is lower than that previously reported for other immigrant groups $(31-45 \%)$. Moreover, while the proportion having low physical activity was high compared to other immigrant groups (Vedoy 2013), half of the participants in this study still reported walking more than 30 min per day.

Despite Somalis being new immigrants to Norway and having widespread economic and social challenges, it seems that Somalis report better health compared to other immigrant groups (SSB 2010). Self-reported health status may also be related to satisfaction with overall quality of life. Results from a recent population-based study on subjective quality of life among immigrants with backgrounds from 12 different countries in Norway showed that the most satisfied immigrants are those with Somali background (Barstad 2018). Compared to immigrants of Somali background, the percentage of immigrants from Iran and Iraq who are dissatisfied with life is close to three times as high. The level of satisfaction among immigrants was correlated with several aspects of living conditions. The high level of life satisfaction reported by Somalis in Norway was proposed to be related to the importance of religion in their life and family structure (Barstad 2018), and such factors could also influence self-perceived health in this group.

\section{Strengths and limitations}

A strength of the current study is that recruitment was community-based, focusing on Norway's largest non-Western 
immigrant population and allowing us to gain an understanding of their self-reported health status. There was also user involvement in the entire study process, which led to high participation.

However, there are several caveats. First, the participants were recruited from only one district. In addition, although every effort was made to include every eligible person of Somali background living in the district, we cannot be sure about how many persons we missed, as population registries for immigrant populations are often outdated. Selection bias may be present, as there were some eligible members of the Somali community in the borough who declined participation or who could not be reached. Experience from other studies on immigrant populations has shown that drawing a random sample from Statistics Norway (SSB) and contacting possible participants through written information does not work well in many immigrant groups. For example, in the Oslo Health Study (HUBRO), only 39\% of the invited immigrants (adults) from non-Western countries participated (Norwegian Institute of Public Health 2019). Another possible limitation is that we do not have information about the importance of culture, family structure, and religion among the participants, which might be relevant for self-perceived health in this population. Furthermore, although self-reported health status is an effective measure for assessing overall health worldwide, the effectiveness in different populations may be attributed to different values and perceptions of health rooted in culture and language, and one should be cautious about interpreting selfrated findings. In our study we have chosen to further categorize the self-ratings of four categories into two to facilitate comparison to other studies (Lindstrom et al. 2001; Kumar et al. 2008). In addition, although it would have been interesting to analytically compare these four groups, this was hampered by the limited number of participants.

\section{Conclusion}

This study provides important insight about the self-reported health status of Somali immigrants in Oslo, underscoring that, compared to other immigrants, a higher proportion of Somalis consider their health to be good or very good. The results showed that self-reported health status varied with gender, age, employment status, and psychosocial conditions, with women generally reporting poorer health status than men. In addition, very high rates of physical inactivity, overweight, and obesity have been reported. The findings from this study could provide direction to healthcare providers for improving health among immigrants, for example through implementing a community-driven and culturally appropriate lifestyle intervention program. Such programs could also target those with multiple morbidities alongside poorer self-reported health, and with a focus on both physical and mental health.
Acknowledgments The authors are grateful to all study participants, the Somali organization, and the Sagene Life Health Centre for their help with this study.

Author contributions AAM and HEM planned the study. AAM carried out the data collection performed data analysis and drafted the manuscript. HEM and BHS contributed data analysis and critically revised the manuscript and contributed to the interpretation of the findings. All authors approved the final version of the manuscript.

Funding information Open Access funding provided by University of Oslo (incl Oslo University Hospital). The Norwegian Health Directorate funded the study.

\section{Compliance with ethical standards}

Conflict of interest The authors confirm that the content of this article is subject to no conflicts of interest.

Open Access This article is licensed under a Creative Commons Attribution 4.0 International License, which permits use, sharing, adaptation, distribution and reproduction in any medium or format, as long as you give appropriate credit to the original author(s) and the source, provide a link to the Creative Commons licence, and indicate if changes were made. The images or other third party material in this article are included in the article's Creative Commons licence, unless indicated otherwise in a credit line to the material. If material is not included in the article's Creative Commons licence and your intended use is not permitted by statutory regulation or exceeds the permitted use, you will need to obtain permission directly from the copyright holder. To view a copy of this licence, visit http://creativecommons.org/licenses/by/4.0/.

\section{References}

Abebe DS, Lien L, Hjelde KH (2014) What we know and don't know about mental health problems among immigrants in Norway. J Immigr Minor Health 16(1):60-67

Ahmed SH, Meyer HE, Kjollesdal MK, Madar AA (2018). Prevalence and predictors of overweight and obesity among Somalis in Norway and Somaliland: a comparative study. J Obes 19(1):878. https://doi. org/10.1186/s12889-019-7101

Ahmed SH, Meyer HE, Kjøllesdal MK, Htet AS, Bjertness E, Madar AA (2019) Comparison of cardiovascular disease risk factors among Somalis living in Norway and Somaliland. Int J Environ Res Public Health 16:13. https://doi.org/10.3390/ijerph16132353

Barstad A (2018). Livskvalitet blant innvandrere. Statistics Norway SSB report 2018/13. [(accessed on 15 November 2019)]; Available online: https://www.ssb.no/sosiale-forhold-og-kriminalitet/artikler-ogpublikasjoner/_attachment/362063?_ts $=165 \mathrm{ccb} 60 \mathrm{e} 80$

Bernadette N. Kumar, Haakon E. Meyer, Anne Johanne Søgaard, Bjørn Heine Strand (2008) The Oslo immigrant health profile. Norwegian Institute of Public Health, Oslo.

Bertisch SM, Pollock BD, Mittleman MA, Buysse DJ, Bazzano LA, Gottlieb DJ, Redline S (2018) Insomnia with objective short sleep duration and risk of incident cardiovascular disease and all-cause mortality: sleep heart health study. Sleep 41:6. https://doi.org/10. 1093/sleep/zsy047

DeSalvo KB, Bloser N, Reynolds K, He J, Muntner P (2006) Mortality prediction with a single general self-rated health question. A metaanalysis. J Gen Intern Med 21(3):267-275 
Gerritsen AA, Bramsen I, Deville W, van Willigen LH, Hovens JE, van der Ploeg HM (2006) Physical and mental health of afghan, Iranian and Somali asylum seekers and refugees living in the Netherlands. Soc Psychiatry Psychiatr Epidemiol 41(1):18-26

Idler EL, Benyamini Y (1997) Self-rated health and mortality: a review of twenty-seven community studies. J Health Soc Behav 38(1):21-37

Iglesias E, Robertson E, Johansson SE, Engfeldt P, Sundquist J (2003) Women, international migration and self-reported health. A population-based study of women of reproductive age. Soc Sci Med 56(1):111-124

Javaheri S, Redline S (2017) Insomnia and risk of cardiovascular disease. Chest. 152(2):435-444. https://doi.org/10.1016/j.chest.2017.01.026

Jervelund SS, Malik S, Ahlmark N, Villadsen SF, Nielsen A, Vitus K (2017) Morbidity, self-perceived health and mortality among nonWestern immigrants and their descendants in Denmark in a life phase perspective. J Immigr Minor Health 19(2):448-476. https:// doi.org/10.1007/s10903-016-0347-9

Kaplan GA, Goldberg DE, Everson SA, Cohen RD, Salonen R, Tuomilehto J, Salonen J (1996) Perceived health status and morbidity and mortality: evidence from the Kuopio ischaemic heart disease risk factor study. Int J Epidemiol 25(2):259-265

La Parra-Casado D, Stornes P, Solheim EF (2017) Self-rated health and wellbeing among the working-age immigrant population in Western Europe: findings from the European Social Survey (2014) special module on the social determinants of health. Eur J Pub Health 27(1): 40-46. https://doi.org/10.1093/eurpub/ckw221

Lindstrom M, Sundquist J, Ostergren PO (2001) Ethnic differences in self reported health in Malmo in southern Sweden. J Epidemiol Community Health 55(2):97-103

Markussen MKG (2018) 'Nobody comes to Baba for advice': negotiating ageing masculinities in the Somali diaspora. J Ethn Migr Stud 1:18. https://doi.org/10.1080/1369183X.2018.1496817

Mavaddat N, Valderas JM, van der Linde R, Khaw KT, Kinmonth AL (2014) Association of self-rated health with multimorbidity, chronic disease and psychosocial factors in a large middle-aged and older cohort from general practice: a cross-sectional study. BMC Fam Pract 15:185. https://doi.org/10.1186/s12875-014-0185-6

Nielsen SS, Krasnik A (2010) Poorer self-perceived health among migrants and ethnic minorities versus the majority population in
Europe: a systematic review. Int J Public Health 55(5):357-371. https://doi.org/10.1007/s00038-010-0145-4

Norwegian Institute of Public Health (2019) The Oslo Health Study (HUBRO). Norwegian Institute of Public Health, Oslo. [Accessed on 15 November 2019]. Available online: https://www.fhi.no/en/ more/health-studies/landsomfattende-helseundersokelser-lhu/ helseundersokelser/the-oslo-health-study-hubro/

Norwegian Institute of Public Health (2018). Social inequalities in health. [Accessed on 15 November 2019]. Norwegian Institute of Public Health, Oslo. Available online: https://www.fhino/en/op/hin/groups/ social-inequalities/\#about-social-inequalities

Rask S, Sainio P, Castaneda AE, Härkänen T, Stenholm S, Koponen P, Koskinen S (2016) The ethnic gap in mobility: a comparison of Russian, Somali and Kurdish origin migrants and the general Finnish population. BMC Public Health 16:340. https://doi.org/10. 1186/s12889-016-2993-1

Roos E, Lahelma E, Saastamoinen P, Elstad JI (2005) The association of employment status and family status with health among women and men in four Nordic countries. Scand J Public Health 33(4):250-260

Statistics Norway (SSB) (2010). Innvandreres helse. Statistics Norway, Oslo. [Accessed on 15 November 2019]. Available online: https:// www.ssb.no/a/publikasjoner/pdf/rapp_201047/rapp_201047.pdf

Statistics Norway (SSB) (2019). "Immigrants and Norwegian-born to immigrant parents." Statistics Norway, Oslo. [Accessed on 15 November 2019]. Available online: https:/www.ssb.no/en/innvbef

Vedoy TF (2013) The role of education for current, former and neversmoking among non-western immigrants in Norway. Does the pattern fit the model of the cigarette epidemic? Ethn Health 18(2):190 210. https://doi.org/10.1080/13557858.2012.700917

Vrålstad S, Wiggen KS (2017) Living conditions among imigrants in Norway 2016. Statistics Norway SSB report 2017/13. Statistics Norway, Oslo. [Accessed on 15 November 2019]. Available online: https:/www.ssb.no/308564/living-conditions-among-imigrants-innorway-2016

Publisher's note Springer Nature remains neutral with regard to jurisdictional claims in published maps and institutional affiliations. 